\title{
Chemical Modification of Urokinase with Bis-imidoesters and Properties of the Intramolecularly Cross-linked Enzyme
}

\author{
Kumio Yokolgawa, ${ }^{*}$ Katsuyuki Tanizawa** and Kenji Soda*** \\ Laboratory of Microbial Biochemistry, Institute for Chemical Research, \\ Kyoto University, Uji, Kyoto 611, Japan
}

Received January 9, 1989

\begin{abstract}
To prepare a chemically modified urokinase that does not dissociate into two peptide fragments upon reduction of its disulfide bridge, we cross-linked the enzyme intramolecularly with various bifunctional imidoesters. The enzyme underwent the intramolecular cross-linking most moderately by the reaction at $4 . \mathrm{C}$ for $5 \mathrm{hr}$ with $3 \mathrm{~mm}$ dimethyl suberimidate in $0.1 \mathrm{M}$ potassium phosphate buffer $(\mathrm{pH}$ 9.0). The cross-linked urokinase isolated by gel filtration with a yield of $25 \%$ showed a specific activity of 76,000 International Units/mg protein, which corresponds to $53 \%$ of that of the native enzyme. Although the modified enzyme was similar to the native urokinase in some properties such as the autocatalytic self-digestion and the low affinity to fibrin, it showed higher in vivo and in vitro stabilities than the native one.
\end{abstract}

Urokinase (UK, EC 3.4.21.31) is a mammalian protease that specifically acts on plasminogen to convert it into plasmin, which then lyses fibrin, the main protein component of blood clots. ${ }^{12}$ Therefore, UK has been widely used in the treatment of acute thromboembolic symptoms. ${ }^{3)}$ The enzyme is synthesized in the kidney as a precursor, a single polypeptide chain (termed single-chain urokinase-type plasminogen activator, scu-PA), converted into the active form composed of two polypeptide chains (heavy chain, mol wt., 31,000; and light chain, 23,000 ) by the proteolytic action of plasmin at $\mathrm{Lys}_{158}-\mathrm{Ile}_{159}$ of scu-PA, ${ }^{4)}$ and secreted into urine after circulation in blood. The light and heavy chains of the active UK are interconnected by a disulfide bridge, thus forming a complex (high molecular weight UK, HMW-UK) with a molecular weight of $54,000{ }^{5)}$

Two modes of conversion of HMW-UK into smaller molecular weight species are known (Scheme 1); one is the formation of the low molecular weight UK (LMW-UK; mol wt., 33,000) during purification of the enzyme ${ }^{6)}$ presumably by self-digestion at two sites in the light chain, ${ }^{7}$ and the other is the dissociation into light and heavy chains by reduction of the disulfide bridge with thiols. ${ }^{5}$ LMW-UK is inferior to the native HMW-UK in physical stability, ${ }^{8)}$ efficiency in activating plasminogen, ${ }^{9)}$ and affinity for fibrin. ${ }^{10)}$ In addition, the light and heavy chains separated by reduction, and also the peptide fragment with a molecular weight of 21,000 , which is released from the enzyme after the self-digestion, are catalytically inactive or only slightly active. Hence, when UK is purified from human urine and used as a therapeutic agent, precautions to avoid conversion into these smaller molecular weight species are required. ${ }^{11)}$

To prepare a more stable UK by chemical modification, we cross-linked the enzyme with bifunctional reagents, bis-imidoesters, which

* On study leave from the Research Department, Wakamoto Pharmaceutical Co., Ashigarakami-gum, Kanagawa 258, Japan.

** Present address: Institute of Scientific and Industrial Research, Osaka University, Mihogaoka 8-1, Ibaraki, Osaka 567, Japan.

*** To whom all correspondence should be addressed. 


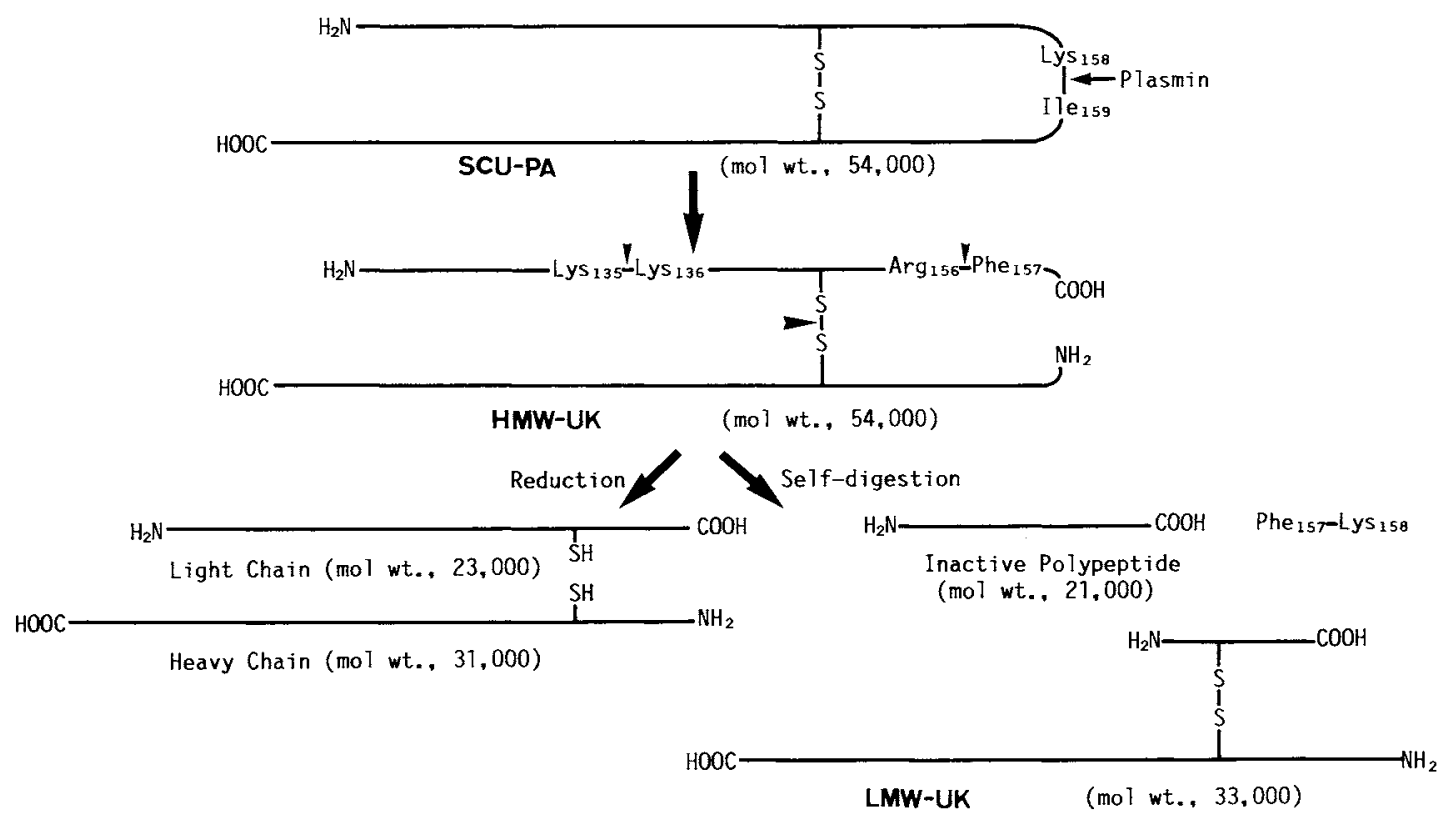

Scheme 1. Molecular Conversion of Urokinase.

have imidoester groups at both ends of the molecule and react highly specifically with amino groups of proteins. ${ }^{12,13)}$ In this paper, we describe synthetic procedures for the intramolecularly cross-linked UK and its properties in comparison with those of the native enzyme.

\section{Materials and Methods}

Materials. HMW-UK was purified to homogeneity from human urine as described previously, ${ }^{11)}$ and confirmed to be free from caseinolytic protease activities by the method of Kunitz. ${ }^{14)}$ Tissue plasminogen activator was purified from the culture of a cell line derived from human normal uterine cells and grown in Hanks' 199 medium. ${ }^{15}$ ) Bis-imidoesters (dimethyl suberimidate dihydrochloride, DMS; dimethyl adipimidate dihydrochloride, DMA; and diethyl malonimidate dihydrochloride, DEM) were obtained from Nakarai Chemicals, Kyoto; bovine fibrinogen containing plasminogen was from Poviet OrganonTeknika, the Netherlands; human fibrinogen $(98 \%$ clottable) was from Sigma, St. Louis, Mo.; thrombin was from Mochida Pharmaceutical, Tokyo; and sodium pentobarbital was from Pitman-Moore, Washington Crossing, N.J. All other chemicals were of the highest purity commercially available.

Reaction with bis-imidoesters. Before the cross-linking reaction, the enzyme was thoroughly dialyzed against
$0.1 \mathrm{~m}$ Tris- $\mathrm{HCl}$, potassium phosphate, sodium bicarbonate, or triethanolamine $\mathrm{HCl}$ buffer $(\mathrm{pH} 9$ or 10$)$, and bis-imidoesters were dissolved in the same buffer. The dialyzed enzyme (final conc., $1 \mathrm{mg} / \mathrm{ml}$ ) was then incubated at $4^{\circ} \mathrm{C}$ for $5 \mathrm{hr}$ with 3 or $30 \mathrm{~mm}$ bis-imidoester in a total volume of $0.3 \mathrm{ml}$. The reaction was stopped by addition of $0.25 \mathrm{ml}$ of $0.5 \mathrm{M}$ potassium phosphate buffer $(\mathrm{pH} 6.3$ ). After the reaction mixture was treated with $25 \mathrm{~mm} \mathrm{~L}$ cysteine at $37^{\circ} \mathrm{C}$ for $1 \mathrm{hr}$ to reductively cleave the disulfide bridge in the UK molecule, the solution was put on a Sephadex G-100 column $(1.9 \times 100 \mathrm{~cm})$ equilibrated with $10 \mathrm{~mm}$ potassium phosphate buffer $(\mathrm{pH} 7.0)$ containing $0.3 \mathrm{M} \mathrm{NaCl}$ and $25 \mathrm{~mm}$ L-cysteine. The dissolved oxygen in the buffer used for the elution was removed by bubbling with nitrogen gas. The fractions containing intramolecularly cross-linked UK, which could be identified as a stable HMW-UK species in the presence of thiols (see below), were pooled and concentrated by ultrafiltration through an Amicon PM-10 membrane.

Analytical methods. The fibrinolytic activity of UK was measured on fibrin gel plates containing plasminogen, ${ }^{16}$ and expressed as International Units (IU $)^{17)}$ with the reference UK (MM-005) which was supplied by the National Institute of Hygienic Sciences, Tokyo. The specific activity was expressed as IU per mg protein. Protein was measured by the method of Lowry et al ${ }^{18)}$ with bovine serum albumin as a standard.

The extent of cross-linking was analyzed by electrophoresis with $0.1 \%$ sodium dodecyl sulfate (SDS) $/ 10 \%$ polyacrylamide gels. ${ }^{19)}$ The stained protein bands were measured with a Shimadzu CS-900 dual wavelength 
chromatoscanner.

The number of free amino groups in the protein was measured with 2,4,6-trinitrobenzenesulfonic acid, ${ }^{20)}$ and that of sulfhydryl groups was measured with 5,5'-dithiobis-(2-nitrobenzoic acid). ${ }^{21)}$

The autocatalytic self-digestion of the enzyme was examined also by SDS/polyacrylamide gel electrophoresis before and after incubation of the UK solution $(1 \mathrm{mg} / \mathrm{ml}$ in $10 \mathrm{~mm}$ potassium phosphate buffer, $\mathrm{pH} 7.4$ ) at $37^{\circ} \mathrm{C}$ for $48 \mathrm{hr}$. Before the incubation, the enzyme solution was sterilized by filtration through a $0.2-\mu$ Millipore membrane.

The affinity of UK for fibrin was measured by affinity chromatography with fibrin-Sepharose, which was prepared by treatment of the human fibrinogen-Sepharose with thrombin. ${ }^{22)}$ The enzyme solutions $(0.5 \mathrm{ml})$ were added to $1 \mathrm{ml}$ of the fibrin-Sepharose, which had been washed with $50 \mathrm{~mm}$ Tris-phosphoric acid buffer ( $\mathrm{pH} 7.6$ ) containing $0.1 \mathrm{M} \mathrm{NaCl}, 25 \mathrm{~mm} \varepsilon$-aminohexanoic acid, and $5 \mathrm{~mm}$ ethylenediaminetetraacetic acid (EDTA). After incubation at $37^{\circ} \mathrm{C}$ for $1 \mathrm{hr}$, the resin was washed with the same buffer, and the bound enzyme was eluted with the buffer supplemented with $1 \mathrm{M} \mathrm{NaCl}$.

The in vitro inhibition of UK by rat plasma was examined by measurement of the remaining UK activity after incubation with rat plasma. The UK solution $(40 \mu$, $13,500 \mathrm{IU} / \mathrm{ml}$ ) was incubated with $4 \mathrm{ml}$ of rat plasma at $37^{\circ} \mathrm{C}$, and $0.2-\mathrm{ml}$ samples of the reaction mixture were taken at various incubation times and acidified (to $\mathrm{pH} 2.0$ ) by addition of $1 \mathrm{~N} \mathrm{HCl}$ to inactivate the remaining protease inhibitors in the plasma. ${ }^{23}$ After standing for $30 \mathrm{~min}$, the solutions were neutralized (to $\mathrm{pH} 7.4$ ) with $1 \mathrm{~N} \mathrm{NaOH}$, and the remaining $\mathrm{UK}$ activity was measured.

The in vivo plasma clearance of UK was studied by injecting the enzyme solution $(9,000 \mathrm{IU} / \mathrm{kg})$ into a femoral vein of Wistar rats weighing about $250 \mathrm{~g}$, which were anesthetized in advance by an intraperitoneal injection of $12.5 \mathrm{mg}$ of sodium pentobarbital. Blood samples were taken from the abdominal aorta at various times after the injection, and mixed with one tenth their volume of $3.8 \%$ sodium citrate (anti-coagulant). The supernatant solution obtained by brief centrifugation was acidified and neutralized as described above, and then was used for the assay of remaining $\mathrm{UK}$.

\section{Results and Discussion}

\section{Preparation of intramolecularly cross-linked $U K$}

To prepare an intramolecularly cross-linked UK that does not dissociate into light and heavy chains on reduction with thiols, we used three kinds of bis-imidoesters (DEM, DMA, and DMS) with different chain lengths. The extent of the intramolecular cross-linking was measured by SDS/polyacrylamide gel electrophoresis and densitometric analysis of the stained protein bands. Since the buffer used in preparing samples for electrophoresis contains $2 \%$ SDS and 5\% 2-mercaptoethanol, ${ }^{19}$ ) the unmodified HMW-UK (mol wt., 54,000) molecules or those which failed to be cross-linked between light and heavy chains would be reductively cleaved and detected as two stained protein bands corresponding to each dissociated chain, but the intramolecularly cross-

Table I. INTRAmolecular CROSS-LINKING OF UROKINASE WITH BIS-IMIDOESTERS

\begin{tabular}{|c|c|c|c|c|c|c|}
\hline $\begin{array}{l}\text { Bis- } \\
\text { imido- } \\
\text { ester }\end{array}$ & $\begin{array}{l}\text { Conc. } \\
\text { (mM) }\end{array}$ & Buffer ${ }^{a}$ & $\mathrm{pH}$ & $\begin{array}{c}\text { Yield }^{b} \\
(A) \\
(\%)\end{array}$ & $\begin{array}{l}\text { Remain- } \\
\text { ing Act. } \\
(B)(\%)\end{array}$ & $\begin{array}{c}B-(100-A)^{c} \\
(\%)\end{array}$ \\
\hline \multirow[t]{8}{*}{ DEM } & \multirow[t]{4}{*}{3} & I & 10 & 29 & 67 & $<0$ \\
\hline & & II & 10 & 23 & 85 & 8 \\
\hline & & III & 10 & 29 & 60 & $<0$ \\
\hline & & IV & 10 & 22 & 73 & $<0$ \\
\hline & \multirow[t]{4}{*}{30} & I & 10 & 49 & 50 & $<0$ \\
\hline & & II & 9 & 45 & 73 & 18 \\
\hline & & III & 10 & 39 & 48 & $<0$ \\
\hline & & IV & 9 & 36 & 71 & 7 \\
\hline \multirow[t]{8}{*}{ DMA } & \multirow[t]{4}{*}{3} & I & 10 & 45 & 21 & $<0$ \\
\hline & & II & 10 & 14 & 86 & 0 \\
\hline & & III & 10 & 40 & 16 & $<0$ \\
\hline & & IV & 9 & 36 & 73 & 9 \\
\hline & \multirow[t]{4}{*}{30} & I & 9 & 40 & 11 & $<0$ \\
\hline & & II & 10 & 20 & 81 & 1. \\
\hline & & III & 9 & 40 & 66 & 6 \\
\hline & & IV & 10 & 39 & 12 & $<0$ \\
\hline \multirow[t]{8}{*}{ DMS } & \multirow[t]{4}{*}{3} & I & 9 & 73 & 9 & $<0$ \\
\hline & & II & 9 & 48 & 81 & 29 \\
\hline & & III & 10 & 49 & 16 & $<0$ \\
\hline & & IV & 9 & 56 & 26 & $<0$ \\
\hline & \multirow[t]{4}{*}{30} & I & 10 & 41 & 4 & $<0$ \\
\hline & & II & 9 & 48 & 60 & 8 \\
\hline & & III & 9 & 30 & 23 & $<0$ \\
\hline & & IV & 10 & 39 & 7 & $<0$ \\
\hline
\end{tabular}

a Buffers used $(0.1 \mathrm{M})$ are Tris- $\mathrm{HCl}$ buffer $(\mathrm{I})$, potassium phosphate buffer (II), sodium bicarbonate buffer (III), and triethanolamine-HCl buffer (IV).

$b$ The yield of intramolecularly cross-linked UK was estimated from densitometric analyses of the stained protein bands after SDS/polyacrylamide gel electrophoresis.

c The enzyme activity expected for the cross-linked UK. 
linked molecules are expected to be detected as a single stained band having the same molecular weight as $\mathrm{HMW}-\mathrm{UK}$ irrespective of the presence of thiols. The amount of intramolecularly cross-linked products measured in this way was variable with the kind of bis-imidoesters used and the reaction conditions (Table I), suggesting the presence of several pairs of reactive amino groups within the distance of possible cross-linkages $(5 \sim 11 \AA)^{24)}$ in the HMW-UK molecule. The highest yield of the cross-linked UK was obtained by the reaction with $3 \mathrm{~mm}$ DMS in $0.1 \mathrm{M}$ Tris- $\mathrm{HCl}$ buffer ( $\mathrm{pH} 9.0$ ). However, the enzyme activity ascribable to the intramolecularly cross-linked UK (calculated by the equation, $B-(100-A)(\%)$, assuming that the molecules not cross-linked intramolecularly are as active as the native $\mathrm{HMW}-\mathrm{UK}$ ) was higher in potassium phosphate buffer than in Tris- $\mathrm{HCl}$ buffer at the same concentration and $\mathrm{pH}$, although the effects of the kind of buffers on the efficiency of cross-linking reaction and on the remaining enzyme activity is unaccountable. When the enzyme was modified with a monofunctional imidoester (methyl butyrimidate hydrochloride) under similar reaction conditions as a control for the modification of amino groups, no significant enzyme activity was lost (data not shown). The protein concentration was fixed at $1 \mathrm{mg} / \mathrm{ml}$ in the cross-linking reaction, because the reactions with bis-imidoesters at higher protein concentrations generally yield intermolecularly cross-linked species. ${ }^{25.26)}$

The intramolecularly cross-linked UK prepared by the reaction with $3 \mathrm{mM}$ DMS in $0.1 \mathrm{M}$ potassium phosphate buffer ( $\mathrm{pH} 9.0$ ) was then isolated by gel filtration with Sephadex G-100 (Fig. 1) after treatment of the reaction mixture with L-cysteine to convert the uncross-linked molecules into light and heavy chains. The fractions (No. $49 \sim 56$ ) corresponding to the intramolecularly cross-linked HMW-UK species were pooled and used in the following experiments after concentration. The final yield was about $25 \%$ in the total UK activity. A minor peak (fraction No. $40 \sim 47$ ) eluted

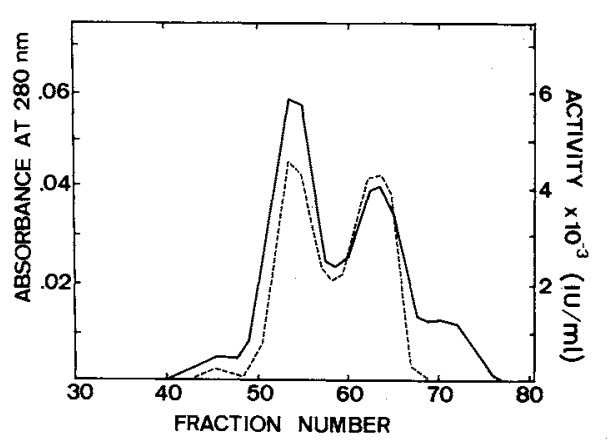

Fig. 1. Gel Filtration of Urokinase Cross-linked with DMS on Sephadex G-100.

The protein concentration (-) was measured by absorbance at $280 \mathrm{~nm}$, and the UK activity (-...-) was assayed on fibrin gel plates. Each fraction was collected in $0.9 \mathrm{ml}$.

slightly ahead of the peak of cross-linked HMW-UK probably corresponds to the intermolecularly cross-linked species with a larger molecular weight, and the two peaks (fractions No. $59 \sim 67$ and $68 \sim 76$ ) after that of the cross-linked HMW-UK correspond to heavy (mol wt., 31,000) and light $(23,000)$ chains, respectively; a significant activity in the heavy chain fractions was restored, probably by reformation of disulfide linkages during the fibrinolytic assay.

\section{Properties of intramolecularly cross-linked UK}

The intramolecularly cross-linked enzyme showed a specific activity of $76,000 \mathrm{IU} / \mathrm{mg}$, which corresponds to $53 \%$ of that of the native HMW-UK. SDS-polyacrylamide gel electrophoresis in the presence and absence of thiols (Fig. 2) revealed that it is composed of a single polypeptide chain. This indicates that the intramolecular cross-linkage was formed between light and heavy chains. In contrast, the native HMW-UK migrated as two stained protein bands on electrophoresis when it was reduced with thiols. ${ }^{27)}$ The number of amino groups remaining in the cross-linked enzyme was only about 8 per mole of the enzyme protein by titration with 2,4,6-trinitrobenzenesulfonic acid. Since the native UK was titrated to contain the sum of 28 free amino groups, this suggests that 20 of them was modified with 10 molecules of the bis- 


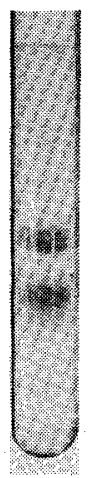

A

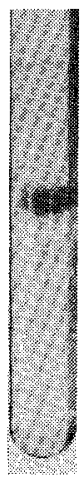

B

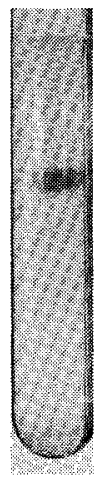

C

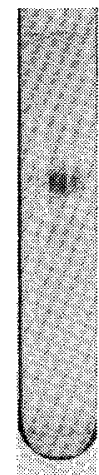

D
Fig. 2. SDS-Gel Electrophoresis of the Native (A, B) and Intramolecularly Cross-linked (C, D) Urokinase.

The enzyme preparations ( $20 \mu \mathrm{g}$ each) were electrophoresed with $(A, C)$ and without $(B, D) 2$-mercaptoethanol in the sample buffer

imidoester. The modification appeared to be specific for amino groups; two sulfhydryl groups could be titrated with 5,5'-dithio-bis(2-nitrobenzoic acid) after reduction of the intramolecularly cross-linked UK with thiols.

HMW-UK is known to catalyze selfdigestion at two sites in the light chain ( Lys $_{135^{-}}$ Lys $_{136}$ and $\mathrm{Arg}_{156}-\mathrm{Phe}_{157}$ ) producing a dipeptide $\left(\mathrm{Phe}_{157}-\mathrm{Lys}_{158}\right)$, an inactive polypeptide with a molecular weight of about 21,000 , and LMW-UK (see Scheme 1), which is composed of the heavy chain and a heneicosapeptide $\left(\right.$ Lys $\left._{136}-\operatorname{Arg}_{156}\right)$. $^{7}$ When the autocatalytic selfdigestion was examined for the intramolecularly cross-linked UK, two major protein bands corresponding to LMW-UK and the inactive peptide were observed in the SDS/ polyacrylamide gel electrophoresis (data not shown). Thus, the cross-linked UK also catalyzes self-digestion. This also shows that the cross-linkages in the cross-linked UK were formed exclusively between the heavy chain and the heneicosapeptide, the inactive peptide with molecular weight of 21,000 not being cross-linked with the heavy chain. Since the heneicosapeptide contains three lysine residues, ${ }^{7)}$ the maximum number of crosslinkages between the heavy chain and the heneicosapeptide is probably three. Therefore,

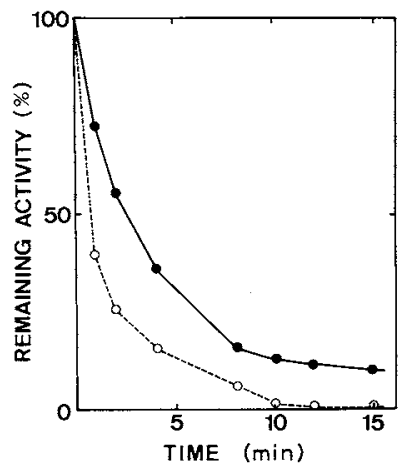

Fig. 3. Plasma Clearance of Urokinase Activity after Intravenous Injection of the Native and Cross-linked Urokinase.

The native $(O)$ and cross-linked (O) UK were injected into Wistar rats, and the remaining UK activity in blood samples taken at indicated times was measured as described in the text.

on the basis of the remaining amino groups in the cross-linked UK (8 groups/mole of enzyme, as described above), at least seven crosslinkages were formed intrapeptidically in the heavy or light chains.

The affinity of the intramolecularly crosslinked UK to fibrin was studied by affinity chromatography with fibrin-Sepharose. About $12 \%$ of the activity of the cross-linked UK put on was found to be bound with the affinity gels, while $14 \%$ of the UK activity was bound when the native HMW-UK was put on. Thus, the intramolecular cross-linking did not affect the affinity of HMW-UK for fibrin, which was higher than that of LMW-UK (no binding with fibrin) but significantly lower than that of the tissue plasminogen activator (almost complete binding with fibrin).

Stabilities of intramolecularly cross-linked UK

Thermostability of the cross-linked UK was examined by measurement of the remaining fibrinolytic activity after incubation at $80^{\circ} \mathrm{C}$ for $1 \mathrm{hr}$. The intramolecularly cross-linked UK retained $20 \%$ of its original activity, but the native HMW-UK lost most of its activity by the incubation, showing that the cross-linked $\mathrm{UK}$ is more thermostable than the native one. Stabilities of the native and cross-linked UK in 
rat plasma were studied both in vitro and in vivo. Although the cross-linked UK was inactivated by incubation with rat plasma to the same extent as the native UK (about $20 \%$ of the original activity remained after incubation for $60 \mathrm{~min}$ with 100 -fold its volume of rat plasma), its in vivo stability was considerably higher than that of the native enzyme (Fig. 3); the half-times of plasma clearance were estimated to be about $2.6 \mathrm{~min}$ for the cross-linked UK and $0.8 \mathrm{~min}$ for the native one. It has been reported that the rapid clearance of UK from blood is mainly due to degradation in the liver, the rate of which is dependent on neither the active site structure of $\mathrm{UK}$ itself nor the carbohydrate side chains. ${ }^{28)}$ Therefore, the longer half-time of plasma clearance of the crosslinked UK likely results from its higher resistance to degradation by liver proteases than the native $\mathrm{UK}$. The resistance is probably ascribable to the intramolecular cross-linking which makes the molecule more rigid and thereby less susceptible to proteolytic cleavages, though the chemical modification lowered the enzyme activity to nearly $50 \%$. Our preliminary observation that the intramolecularly cross-linked UK is digested by trypsin more slowly than the native HMW-UK also supports the above suggestion.

In conclusion, the intramolecularly crosslinked UK is probably advantageous for clinical use and in studies on the in vivo behavior of UK because of its higher stabilities.

Acknowledgment. We thank Dr. M. Izumiya and Dr. T. Kobayashi, Wakamoto Pharmaceutical Co., Ltd., for their helpful discussions.

\section{References}

1) T. Astrup and I. Sterndorff, Proc. Soc. Exptl. Biol. Med., 81, 675 (1952).

2) L. Lorand, "Methods in Enzymology," Vol. XLV, ed. by L. Lorand, Academic Press Inc., New York, 1976, p. 31.

3) A. Klausner, Biotechnology, 1, 330 (1983).
4) W. E. Holmes, D. Pennica, M. Blaber, M. W. Rey, W. A. Guenzler, G. J. Steffens and H. L. Heyneker, Biotechnology, 3, 923 (1985).

5) M. Nobuhara, M. Sakamaki, H. Ohnishi and Y. Suzuki, J. Biochem. (Tokyo), 90, 225 (1981).

6) W. F. White, G. H. Barlow and M. M. Mozen, Biochemistry, 5, 2160 (1966).

7) J. Schaller, H. Nick, E. E. Rickli, D. Gillessen, W. Lergier and R. O. Studer, Eur. J. Biochem., 125, 251 (1982).

8) H. Sumi, K. Sasaki and M. Muramatsu, Acta Haem. Jpn., 41, 766 (1978).

9) J. C. Lormeau, J. Goulay, E. G. Vairel and J. Choay, "Fibrinolysis," ed. by P. J. Gaffney and S. BalkuvUlutin, Academic Press Inc., London, 1978, p. 77.

10) H. Sumi, H. Mihara and N. Toki, Acta Haem. Jpn., 44, 1044 (1981).

11) K. Yokoigawa, K. Tanizawa and K. Soda, Agric. Biol. Chem., 48, 1587 (1984).

12) M. J. Hunter and M. L. Ludwig, J. Am. Chem. Soc., 84, 3491 (1962).

13) L. Wofsy and S. J. Singer, Biochemistry, 2, 104 (1963).

14) M. Kunitz, J. Gen. Physiol., 30, 291 (1947).

15) H. Fukao, C. Matsuo, O. Matsuo, K. Yokoigawa, K. Akiba and T. Ohmura, Tissue Culture Res. Commun., 5, 106 (1986).

16) J. Ploug and N. O. Kjeldgaard, Biochim. Biophys. Acta, 24, 278 (1957).

17) G. H. Barlow, "Methods in Enzymology," Vol. XLV, ed. by L. Lorand, Academic Press Inc., New York, 1976, p. 239.

18) O. H. Lowry, N. J. Rosebrough, A. L. Farr and R. J. Randall, J. Biol. Chem., 193, 265 (1951).

19) K. Weber and M. Osborn, J. Biol. Chem., 244, 4406 (1969).

20) R. Fields, Biochem. J., 124, 581 (1971).

21) G. L. Ellman, Arch. Biochem. Biophys., 82, 70 (1959).

22) D. L. Heene and F. R. Matthias, Thrombo. Res., 2, 137 (1973).

23) T.-C. Wun, W.-D. Schleuning and E. Reich, J. Biol. Chem., 257, 3276 (1982).

24) K. Peters and F. M. Richards, Ann. Rev. Biochem., 46, 523 (1977).

25) A. Dutton, M. Adams and S. J. Singer, Biochem. Biophys. Res. Commun., 23, 730 (1966).

26) D. Wang, G. Wilson and S. Moore, Biochemistry, 15, 660 (1976).

27) M. E. Soberano, E. B. Ong, A. J. Johnson, M. Levy and G. Schoellmann, Biochim. Biophys. Acta, 445, 763 (1976).

28) D. Collen, F. De Cock and H. R. Lijnen, Thromb. Haemostas., 52, 24 (1984). 